\title{
Peri-tumoral neural niche in brain metastasis from breast
} \section{cancer}

\author{
Rahul Jandial* and Khairul I Ansari \\ Division of Neurosurgery, Beckman Research Institute, City of Hope, CA, USA
}

Breast cancer brain metastases (BBM) are known to develop years to decades after initial diagnosis, even in the presence of early circulating tumor cells in the blood. This clinical latency suggests that colonization of the brain is the most challenging step of the metastatic cascade. The rare cells that traverse an intact blood brain barrier are devoid of tumor neovasculature and rely on early proliferative cues from the brain microenvironment. The "seed and soil" hypothesis suggests metastatic breast cancer cells require favorable interactions in neuronal microenvironment to successfully form metastases. Our research is focused on revealing the neural niche's contribution towards bidirectional interaction between invading breast cancer cells and resident glial cells thoughout successful brain colonization. The image depicts the expression of human epidermal growth factor receptor 2 (Her2) in metastatic breast cancer cells and glial fibrillary acidic protein (GFAP) in reactive astrocytes within neural microenvironment. The reactive astrocyte deleased Brain-derived neurotrophic factor (BDNF) activates its cognate receptor Tropomyosin receptor kinase $B(\operatorname{TrkB})$ that heterodimerizes with Her2 and activates Her2 signaling. This activation of TrkB and Her2 signaling provide adaptive advantages to the invading tumor cells facilitaing brain colonization. In a feed-backloop the invading tumor cells affect neural microenvironment and affect behaviors of the resident glial cells.

Copyright: (C2016 Jandial R. This is an open-access article distributed under the terms of the Creative Commons Attribution License, which permits unrestricted use, distribution, and reproduction in any medium, provided the original author and source are credited.

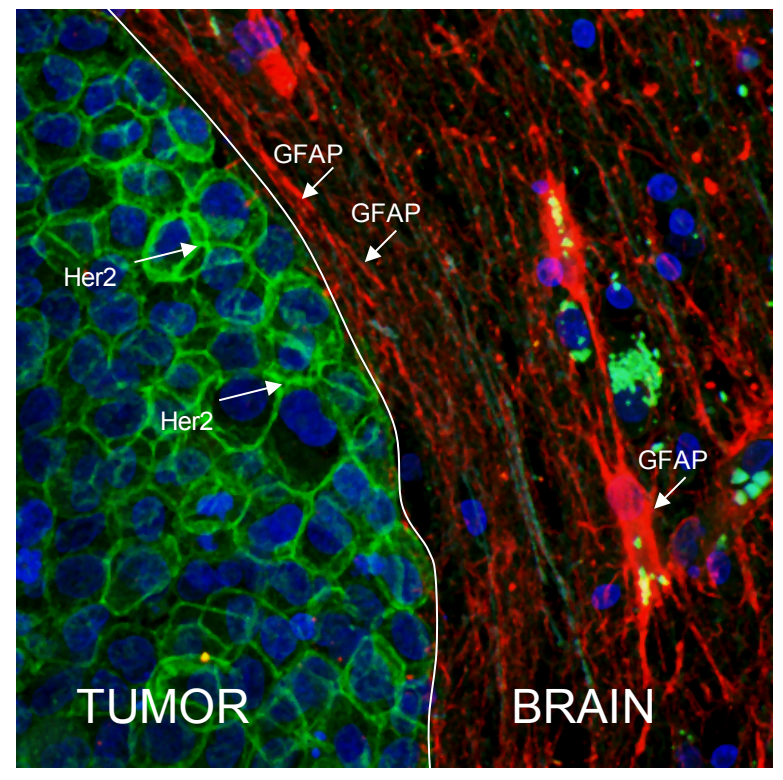

Correspondence to: Rahul Jandial, MD, PhD, Division of Neurosurgery, Beckman Research Institute, City of Hope, 1500 E. Duarte Rd, Duarte, CA 91010, USA, E-mail: Rjandial@coh.org

Received: June 14, 2016; Accepted: July 01, 2016; Published: July 04, 2016 